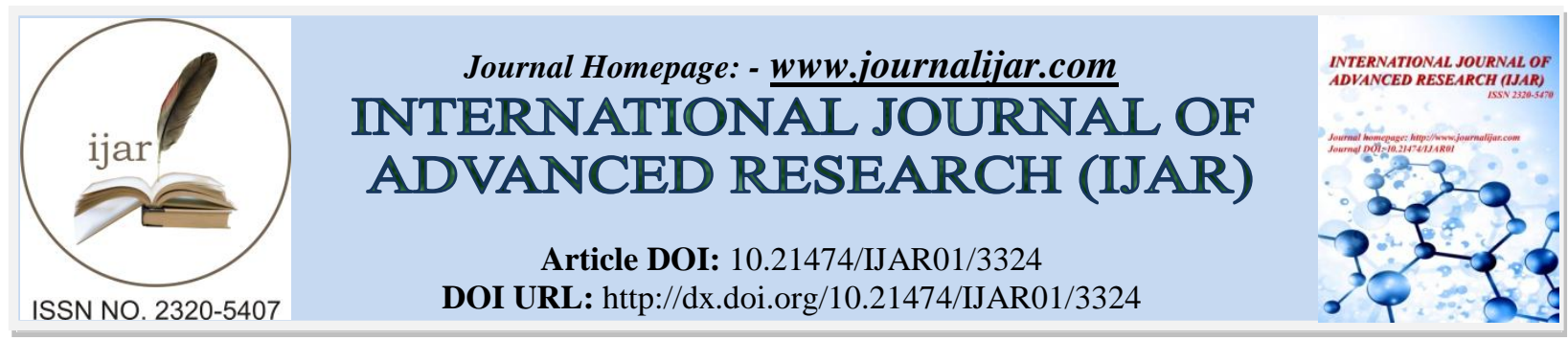

RESEARCH ARTICLE

\title{
IMPACTS OF INFORMATION AND COMMUNICATION TECHNOLOGY (ICT) IN LOGISTIC MANAGEMENT IN UNILEVER KENYA LIMITED.
}

Maurice M. Opiyo.

Rongo University, P.O. Box 103-40404, Rongo, Kenya.

\section{Manuscript Info}

(.........................

Manuscript History

Received: 26 December 2016

Final Accepted: 15 January 2017

Published: February 2017

Key words:-

Impacts, Information, Communication

Technology, Logistic Management,

Kenya

\section{Abstract}

ICT deals with the use of electronic computers and computer software to convert, store, protect, process, transmit and retrieve information, securely. Recently it has become popular to broaden the term to explicitly include the field of electronic communication so that people tend to use the abbreviation ICT (Information and Communications Technology (Greenwood, 1997). Due to the widespread adoption of the supply chain view by commercial enterprises all over the world, the business management providers are increasingly required to offer global logistics service packages to better satisfy customer needs. Information and Communication Technologies (ICT) play a key role in this process, assuring the linkages between chain participants as well as a more effective control of time, cost, and quality of the service rendered. Nevertheless, introduction of ICT is not equally distributed in the industry. In the case of manufacturing and production, crucial business links and interlinks lines seem to be comparatively slow in implementing ICT in comparison with parcel delivery companies or large freight forwarders.

The increasing importance of ICT for logistics as well as for the Supply Chain Management (SCM) presents business world with two alternatives: either to survive in a low-cost world of business providers or to pursue the expensive and problematic path of becoming valueadded providers through an extensive use of ICT. Introduction of ICT in logistics provides management an integrated capacity of assurance and reliable communication advantage at every stage of operations, which encompasses activities like cargo tracing, answering customers complain, inquiry billing and information management (Baily 2005). The use of E-mail and other related bulk Short Message Services (EMS) that comes with the application and adoption of Information and Communications Technology provides quick and documented communications with customers and other important stakeholders. This as compared with manual operations besides providing customer value saves costs and time in operations a great deal 


\section{Introduction:-}

Information and Communication Technology (ICT), as defined by the Information Technology Association of America (ITAA), is "the study, design, development, implementation, support or management of computer-based information systems, particularly software applications and computer hardware (Donald 1997). Information and Communications Technology (ICT) is an increasingly powerful tool for participating in global markets; promoting political accountability; improving the delivery of basic services; and enhancing local development opportunities. But without innovative ICT policies, many people in developing countries - especially the poor - will be left behind. ICT deals with the use of electronic computers and computer software to convert, store, protect, process, transmit and retrieve information, securely. Recently it has become popularto broaden the term to explicitly include the field of electronic communication so that people tend to use the abbreviation ICT (Information and Communications Technology). It is common for this to be referred to as IT \& T in the Australasia region, standing for Information Technology and Telecommunications (Greenwood, 1997).

In today's Supply Chain Management (SCM) practices, a successful strategy depends more on the performance of Third Party Logistics service providers (3PLs) (Kenneth, Brian, 2006). Accordingly, logistics providers play a key integrative role linking the different supply chain elements by the management of information flows connected with the entire delivery process of goods (Chopra, 2007). Information and Communication Technology is becoming one of the main drivers of change in the industry, posing new strategic challenges to logistics companies and management. Information and Communication Technology (ICT) developments are more and more influencing the transport and logistics service market and give rise to new organizational forms for these services. For example, the volume of electronic communication along the supply chain is fast growing together with the electronic exchanges of transport documentation, invoices, order instructions and payments (Trilog, 1999). This has created an increasing need to support customers supply chains requirements through an effective use of ICT (Meindl, 2007).

According to Saunders (1997), ICT in Logistics is the application of computer software and / or automated machinery to improve the efficiency of logistics operations. Typically this refers to operations within a warehouse or distribution center, with broader tasks undertaken by supply chain management systems and enterprise resource planning systems. The information systems applications in the field of logistics and supply chain management are not new, and have a long history dating back in the 1960s, when early Electronic Data Interchange (EDI) were first used; predating the use of computer power. An early example was maintenance of inventory records on ledger cards which at first were manually up-dated and later became semi-mechanically updated using magnetically encoded data. As such the computer has facilitated faster data processing and allowed significantly more data and information to be handled. It is not therefore outrageous to evaluate the impact of ICT on the Logistics Management of Unilever Kenya Limited.

The need to serve customers in a flexible and speedy manner has forced manufacturers and distributors to effectively exploit ICT by creating "global nervous system" that link a continuous flow of supply and demand information between suppliers and customers; (Kennet et al., 1996). This has raised the level of information intensity in logistics and management as well as supply chain management services. In this perspective ICT has developed and have increasingly influenced the transport and logistics services industry, shifting the focus from a physical to a more electronic one and giving rise to new organizational forms for those services.

Previous studies revealed that growth in volumes of electronic communications along the logistics management and supply chain management, was expected to double by the year, 2005 thus electronic exchanges of transport documentation, invoices, orders instructions and payments are focused to grow 59\% (Trilog, 1999). This has led to an increasing interest in assessing the effect of ICT on the transport and logistics industry.

According to Donald (1997), automated cranes (also called automated storage and retrieval systems) provide the ability to input and store a container of goods for later retrieval. Typically cranes serve a rack of locations, allowing many levels of stock to be stacked vertically, and allowing far high storage densities and better space utilization than alternatives. Further, automated conveyors allow the input of containers in one area of the warehouse, and either through hard coded rules or data input allows destination selection. Business Control software: provides higher level functionality, such as identification of incoming deliveries / stock and scheduling order fulfillment, assignment of stock to a large set of locations (Peter 2000). 
Mobile technology; Radio data terminals: these are hand held or truck mounted terminals which connect wirelessly to logistics automation software and provide instructions to operators moving throughout the warehouse. Many also have in-built barcode scanners to allow identification of containers. Bar codes allow the automatic capture of data without use of the computer keyboard, which is slow and error prone. Software Integration software: this provides overall control of the automation machinery and for instance allows cranes to be connected up to conveyors for seamless stock movements (Lysons 1996).

According to Bailey (1978), Uneliver Kenya receives stock of a variety of products from suppliers and store these until the receipt of orders from customers, whether individual buyers (e.g. mail order), retail branches (e.g. chain

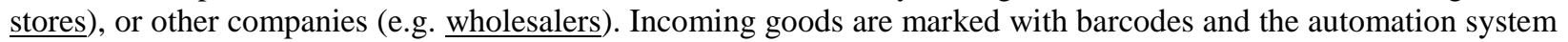
notified of the expected stock. On arrival, goods are scanned and thereby identified, and taken via conveyors, sortation systems, and automated cranes into an automatically assigned storage location. Automated Goods Retrieval for Orders: On receipt of orders, the automation system is able to immediately locate goods and retrieve them to a pick face location. Automated dispatch processing: Combining knowledge of all orders placed at the warehouse the automation system can assign picked goods into dispatch units and then into outbound loads (Bailey1978).

\section{Impacts of ICT on Management:- Transparency/ or Accountability:-}

According to Lysons (1996) asserted that there are different tools available to coordinate effectively the supply chain. Technological tools constitute the most important management tools because these offer fast and convenient channels of communication within the organization and of the organization with its suppliers and customers. The predecessor of current technological channels of incoming and outgoing communication is the telephone, faxmachine and computers, which are still useful to modern businesses. However, these technological tools were enhanced by the internet and its unlimited potential for businesses. The internet provides a channel of communications that covers contract negotiations, buying and selling of products, monitoring of the transport of goods, payment of goods and services, coordination of internal tasks and a lot more benefits (Lysons, 1996).

\section{Record Keeping:-}

Stevens (1995) defines automation of records and documents as the storage and transmission of business documents via computer system. With the continuous implementation of ICT in various areas of logistics management which has reduced the manual way of keeping records and exchange of documents between the buyer and supplier in what is being termed as paperless trading. Automation of records and documents has resulted to e-business concept which relies on an automated business system.

Electronic business methods enable companies to link their internal and external data processing systems more efficiently and flexibly, to work more closely with suppliers and partners, and to better satisfy the needs and expectations of their customers. In practice, e-business is more than just e-commerce. While e-business refers to more strategic focus with an emphasis on the functions that occur using electronic capabilities, e-commerce is a subset of an overall e-business strategy ((Peter Baily 2005).Due to increased rise to paperless trading there has been need to implement the electronic data interchange (EDI) concept where partners are free to use any method for the transmission of documents. In the past one of the more popular methods was the usage of a bisync modem to communicate through a Value Added Network (VAN). Some organizations have used direct modem to modem connections and Bulletin Board Systems (BBS), and recently there has been a move towards using some of the many Internet protocols for transmission, but most EDI is still transmitted using a VAN. In the healthcare industry, a VAN is referred to as a "Clearinghouse". EDI and other similar technologies save a company money by providing an alternative to, or replacing information flows that require a great deal of human interaction and materials such as paper documents, meetings, faxes, email (Peter 2000).

According to Lysons (1996), business of keeping records in hard copy files should be a thing of the past, with the new technology that is available, every government office needs to automate, so to facilitate retrieval of supply chain information when needed, it can be made available in real time. Office automation refers to the varied computer software used to digitally create, collect, store, manipulate and relay office information necessary for accomplishing basic tasks and goals. The backbone of office automation is a LAN, which allows users to transmit data, e-mail. 


\section{Distribution efficiency:-}

Occurs when goods and services are received by those who have the greatest need for them. This is made possible by use of Distribution Resource Planning (DRP) which is a method used in business administration for planning orders within a supply chain. DRP enables the user to set certain inventory control parameters (like a safety stock) and calculate the time-phased inventory requirements (Menon 2004).

The on-hand inventory at the end of a period.DRP has the following variables the backordered demand at the end of a period, the required quantity of product needed at the beginning of a period, the constrained quantity of product available at the beginning of a period, the recommended order quantity at the beginning of a period. For DRP to function the following information is required, demand in a future period, the scheduled receipts at the beginning of a period, the safety stock requirement for a period and the on-hand inventory at the beginning of a period (Ammer, 1986).

It is all inventory control and scheduling technique that applies the MRP principle and distribution environment integration, the special needs of distribution and a time face plan of events that affect inventory, it's the rates IT tool for controlling inventory to the distribution system of organization.DRP is guided by customer demand. It allocates inventory from the central warehouse to the various distribution centres based on demand patterns, safety stock provisions, order quantity, reorder level and average performance cycle length. DRP also coordinates the finished goods required across the distribution network, the success of this system depends on the accuracy of performance with respect to location and time of requirement across the system is necessary for system effectiveness (Stevens, 1995).

Logistics professionals need to make greater use of available technology to drive positive and efficient business results. Systems solution is driven by knowledgeable people who clearly understand the business challenge and apply technology appropriately to this challenge one side-effect of technology is that it provides a solid short-term solution but cannot adapt to future needs. System designers must carefully assess the functionality required to allow the company to grow over time and adapt to changing logistics requirements. Without systems flexibility, logistics executives will continuously request funding for new or customized systems, leading to the perception that logistics is just a cost center worse yet, a black hole of continuous investment (Peter 2000).

Despite the risks in the systems problems, information and operations systems for logistics management will continue to be vitally important in leveraging logistics to achieve a competitive advantage. Third party logistics providers within the last decade, there has been a direct positive correlation between the role of systems in improving logistics programs and the increasingly important role of third party providers (Bailey1978).Organizations must continually invest in logistics systems to support their core business this allows shippers to avoid systems development efforts by tapping into tap an existing infrastructure. Many companies have flat or declining information technology budgets, and logistics systems are well down the priority list for corporate systems investments. There should be incentive that drives logistics providers to adopt and implement technologies that deliver an attractive ROI, or risk extinction (Hooligan1988).

One of the most exciting tools for applying systems to logistics management and changing the way people work is the internet. The shared network of the World Wide Web can link supply chain systems and partners through one identical, user-friendly interface accessible by anyone with a web browser. This enables complete and seamless supply chain integration, while still allowing providers to develop the unique software required for their specific applications

(Kumpe1988). Today the internet remains more promise than panacea, to catch up to early adopters of internet commerce by implementing applications that are too often long on technology, but short on real value. There need to recognize the need to logistics excellence. These can eventually be achieved by those who focus their time and energy on understanding the business challenge, then use information and operations systems as tools to continuously improve process (Kumpe1988).

\section{Cost reduction:-}

One of the aims of each business is to reduce cost to the minimum so as to realize profit, e-procurement aims to reduce cost and enhance efficiency.An important part of many B2B sites, e-procurement is also sometimes referred to by other terms, such as supplier exchange. Typically, e-procurement Web sites allow qualified and registered users to look for buyers or sellers of goods and services. Depending on the approach, buyers or sellers may specify 
costs or invite bids (Bailey1978).Transactions can be initiated and completed. Ongoing purchases may qualify customers for volume discounts or special offers. E-procurement software may make it possible to automate some buying and selling. Companies participating expect to be able to control parts inventories more effectively, reduce purchasing agent overhead, and improve manufacturing cycles. E-procurement is expected to be integrated with the trend toward computerized supply chain management (Peter 2000).

According to Peter Baily (2005), Electronic funds transfer or EFT refers to the computer-based systems used to perform financial transactions electronically. Some of the transactions performed include sale, refund, withdrawal, deposits, cash backs etc. EFT transactions require communication between numbers of parties. When a card is used at a merchant or ATM, the transaction is first routed to an acquirer, then through a number of networks to the issuer where the cardholder's account is held.

A transaction may be authorized offline by any of these entities through a stand-in agreement. Stand-in authorization may be used when a communication link is not available, or simply to save communication cost or time. Stand-in is subject to the transaction amount being below agreed limits. These limits are calculated based on the risk of authorizing a transaction offline, and thus vary between merchants and card types. Offline transactions may be subject to other security checks such as checking the card number against a 'hotcard' (stolen card) list, velocity checks (limiting the number of offline transactions allowed by a cardholder) and random online authorization (Hooligan1988).

\section{Conclusion:-}

The impacts of ICT in logistic management are; transparency, record keeping, distribution efficiency and cost reduction. This was demonstrated by the study findings where average of $75 \%$ of the respondents were presented to have accepted yes. The level of ICT in logistic employed are ineffective and this negatively affects effectiveness and efficiency of logistic management activities. Information communication technology ensures transparency among employees when conducting logistic activities which provides information for holding employees accountable for their actions, ICT provides clear communication channels for employees in every stage of logistic. Computerization of record keeping ensures elimination of manual way of storage and transmission of documents across the logistic network which reduces overall cost of record keeping. Records and documents stored electronically ensure security and easier retrieval when required. ICT in logistic management aims to enhance distribution efficiency and information communications technology is an important factor for any organization to achieve efficiently their longterm goals. Information communications technology provides the tool for the efficient coordination of the different process links throughout the logistic network. The main aim of the organization integration of ICT with logistic activities is to reduce cost; ICT management, e-procurement aims to reduce the cost of procurement process; reduces the cost of storage and processing of documents, inventory

\section{Recommendations:-}

Transparency should aim to hold employees accountable for any action they take in the line of their duty. Information communication technology should encourage transparency in the whole of logistic network; ICT should be made more effective to minimize malpractices in logistic management, enterprise resource planning system should be implemented so as to provide information in every stage of logistic management. Automation of records keeping eliminates the need to store documents manually; the security of documents is improved, unauthorized users are denied accessibility as computer are have passwords which restricts unauthorized users. To reduce the security risks of the documents stored electronically, there is need to back up records which are vulnerable to virus, Trojan attacks which crash computer systems and destroying logistic information.

ICT should aim to make logistic management activities as efficient as possible, Just in Time (JIT) system should be implemented in inventory management which will avail materials in just the right time, right place to make the right amount of products, distribution resource planning (DRP) should be implemented to ensure efficient distribution of materials. The management of should implement ICT infrastructure which is capable of reducing the cost in logistic management, all documents, records and inventory management should be computerized, e-procurement should be implemented to reduce the cost in procurement process, Distribution resource planning (DRP) should be implemented so as to reduce the cost of distribution of products. 


\section{References:-}

1. Ammer (1986) Material Management \& Purchasing; Longman publishers; 4th Edition

2. Bailey P. (1978) Purchasing \& Supply Management; Pearson Publishers; $4^{\text {th }}$ Edition

3. Donald W. D. (1997) Purchasing \& Materials; British Press; $4^{\text {th }} \& 5^{\text {th }}$ Edition (1984)

4. Greenwood, M C. (1997). Continuous Flow Manufacturing in a Quicken Market; New York Press; 2nd Edition

5. Hooligan, J. (1988). Exploiting the Industrial Supply Chain, in Mortimer; IFS Publications; 2nd Edition.

6. Kennet \& Brian (2006) Purchasing and Supply Chain Management (2006) $7^{\text {th }}$ Edition Hampshire Great Britain

7. Kenneth Lysons and Brian Farrington (2006) Purchasing and Supply Chain Management (2006) Ashfold Color Press, Hants Great Britain $7^{\text {th }}$ Edition

8. Kumar and Nirmalya (1996) The power of trust in manufacturer-Retailer Relationship. Havard Business Review (November-December 1996): 92-106

9. Kumpe, P.T. (1988). Manufacturing: The Case for Vertical; Integration, Harvard Business Review, $2^{\text {nd }}$ Edition.

10. Lyons C. K.,(2002). Purchasing M \& F; Pitman Publishers,(1981) $5^{\text {th }}$ Edition Macbeth, D., F (1999) Supply Chain Management, Purchasing and Supply

11. Lysons C. K. (1996). Purchasing M \& F; Pearson, $5^{\text {th }}$ Edition

12. Management; Pearson Publishers; 1st Edition;

13. Meindl (2007) Supply Chain Management (2007) $3^{\text {th }}$ Pearson Prentice Hall, United States of America

14. Menon K (2004). Purchasing Management; Peak Publishers $3^{\text {rd }} \& 4^{\text {th }}$ Edition

15. Peter B.H (2000) Purchasing Principle \& Techniques ELBS with Pitman Publishers. $3^{\text {rd }}$ Edition

16. Peter Baily (2005) Purchasing Principles and Management (2005) $9^{\text {th }}$ Edition Hampshire Great Britain

17. Saunders, M.J. (1997). Strategic Purchasing and Supply Chain Management, Bell and Bain Ltd., Glasgow; Second Edition.

18. Stevens J. M. (1995), The Purchasing \& Marketing Interface Pitman Publishers; 3rd Edition 